\title{
From mild cognitive impairment to subjective cognitive decline: conceptual and methodological evolution
}

Yu-Wen Cheng'

Ta-Fu Chen ${ }^{2}$

Ming-Jang Chiu' ${ }^{2,3}$

'Department of Neurology, National Taiwan University Hospital, Hsin-

Chu Branch, Hsin-Chu, Taiwan; ${ }^{2}$ Department of Neurology, National Taiwan University Hospital, College of Medicine, National Taiwan University,

Taipei, Taiwan; ${ }^{3}$ Department of Psychology, College of Science, National Taiwan University, Taipei, Taiwan
Correspondence: Ming-Jang Chiu Department of Neurology, National Taiwan University Hospital, College of Medicine, National Taiwan University, Number 7, Chung-Shan South Road, Taipei 100, Taiwan

Tel +886223123456 ext 65339

Fax +886223418395

Email mjchiu@ntu.edu.tw
This article was published in the following Dove Press journal:

Neuropsychiatric Disease and Treatment

16 February 2017

Number of times this article has been viewed

\begin{abstract}
Identification of subjects at the early stages of Alzheimer's disease (AD) is fundamental for drug development and possible intervention or prevention of cognitive decline. The concept of mild cognitive impairment (MCI) evolved during the past two decades to define subjects at the transitional stage between normal aging and dementia. Evidence from cross-sectional and longitudinal studies has shown that MCI is associated with an increased risk of positive $\mathrm{AD}$ biomarkers and an increased annual conversion rate of $5 \%-17 \%$ to $\mathrm{AD}$. The presence of $\mathrm{AD}$ biomarkers in subjects with MCI was associated with an even higher risk of progression to dementia. However, earlier clinical trials for pharmacotherapy in subjects with MCI were disappointing. To extend the spectrum of $\mathrm{AD}$ to an earlier stage before $\mathrm{MCI}$, subjective cognitive decline (SCD) was introduced and was defined as self-reported cognitive decline before the deficits could be detected by cognitive tests. Subjects with SCD have an increased risk of underlying AD pathology. However, SCD can also develop secondary to other heterogeneous etiologies, including other neurodegenerative and psychiatric diseases, personality traits, physical conditions, and medication use. Several clinical and biomarker features were proposed to predict risk of conversion to AD in subjects with SCD. Further longitudinal studies are needed to support the validity of these high-risk features.
\end{abstract}

Keywords: mild cognitive impairment, subjective cognitive decline, preclinical Alzheimer's disease, Alzheimer's disease

\section{Preclinical stages of Alzheimer's disease as a potential therapeutic target}

Alzheimer's disease (AD) is the most important cause of dementia in the elderly population. Although much effort has been made in the development of therapies to stop the progression of $\mathrm{AD}$, acetylcholinesterase inhibitors and the $N$-methyl-D-aspartate (NMDA) receptor antagonist memantine are the only two classes of medication that have modest positive effects on cognitive decline. ${ }^{1,2}$ Based on the evidence from neuroimaging, neuropathological and biochemical studies, it was established that the pathophysiological process of AD begins years or even decades before cognitive decline. $^{3-5}$ One possible explanation for the failure of previous drug trials is that it may be too late to start treatment when there is evident cognitive impairment, and neuronal injury and synaptic dysfunction have advanced beyond the point of reversibility. Identification of subjects at an early stage is crucial for therapeutic intervention and possible prevention of cognitive decline. During the past several decades, two approaches have been used to identify subjects with early AD. One approach is to look for subtle cognitive changes before overt dementia, and the other approach is 
to look for surrogate biomarkers of Alzheimer's pathology. On the clinical spectrum of $\mathrm{AD}$, there is no definite cut-off point to discriminate between normal aging and dementia. By using more sensitive neuropsychological tools, subjects at the early end of the AD spectrum could be identified, but possibly at the expense of increased diagnostic uncertainty. The concept of preclinical AD evolved in response to the need to identify subjects with Alzheimer's pathological process before the onset of significant cognitive decline. Preclinical AD was initially used to describe subjects with neuropathological evidence of AD without detectable cognitive changes. ${ }^{3}$ Following the development of biochemical and neuroimaging biomarkers, the National Institute on Aging and the Alzheimer's Association (NIA-AA) recommended a staging schema for preclinical AD based on biomarker status. ${ }^{6}$ Subjects without cognitive decline are classified as stage I based on the presence of amyloidosis biomarkers, and as stage II if biomarkers for both amyloidosis and neuronal injury are present. Subjects with biomarkers for both amyloidosis and neuronal injury and subtle cognitive decline (well above the cut-off for mild cognitive impairment [MCI]) are classified as stage III. The application of biomarkers can help specify the earliest pathophysiological changes of $\mathrm{AD}$ and increase diagnostic certainty in subjects with subtle cognitive decline.

\section{Mild cognitive impairment: the transition from normal aging to dementia}

Since the early 19th century, researchers have attempted to identify the transitional state from normal aging to pathological cognitive decline. The evolution of diagnostic criteria for MCI is summarized in Table 1. The term mild cognitive impairment was first used to describe stage 3 of the global deterioration scale (GDS) for aging and dementia. At stage 3 of the GDS, subjects exhibit subtle deficits in cognition that affect complex occupational and social activities but do not yet meet the criteria for dementia. ${ }^{7,8}$ In 1999, Petersen et al redefined $\mathrm{MCI}$ as a syndrome of cognitive decline beyond that expected for an individual's age and education level, but that does not notably interfere with activities of daily living. ${ }^{9}$ The original criteria focused on memory performance, which is often the earliest symptom of AD. However, decline in other cognitive domains can develop during or even before memory impairment. To broaden the concept of MCI, the Key Symposium was held in Sweden and published consensus criteria for MCI in 2004. ${ }^{10,11}$ To emphasize the heterogeneity of the clinical presentation and multiple underlying etiologies of MCI, the Key Symposium criteria expanded the definition of MCI beyond the memory domain and further classified MCI into three subtypes: amnestic, multiple domain, and single non-memory domain MCI. Early population-based studies showed that amnestic MCI affects $5 \%-10 \%$ of the elderly population. ${ }^{12}$ Adapting the expanded MCI criteria, the prevalence of MCI increased to $8 \%-25 \%$ of the elderly population aged $\geq 60$ years. ${ }^{13,14}$ In a systematic review published in 2013, the annual conversion rate of $\mathrm{MCI}$ to $\mathrm{AD}$ ranged from $7.5 \%$ to $16.5 \%$ per personyear for clinic-based studies, and from $5.4 \%$ to $11.5 \%$ for community samples. ${ }^{15}$ Consistent with previous findings that identified memory decline as the initial symptom of AD, amnestic MCI was associated with a higher risk of progression to AD in several longitudinal studies. ${ }^{16-19}$

In 2011, the NIA-AA convened workgroups to revise diagnostic criteria for $\mathrm{AD}$ and its preclinical stages. ${ }^{6,20,21}$ The NIA-AA core clinical criteria for MCI due to AD were essentially adopted from the Key Symposium criteria, while incorporation of biochemical and neuroimaging biomarkers was recommended in research settings to stratify the level of certainty of underlying Alzheimer's pathology. ${ }^{21}$ During the past 10 years, several biomarkers have been shown to predict the risk of progression to dementia. These risk factors include amyloid-specific biomarkers, neuronal injury biomarkers, and vascular comorbidities. The carrier status

Table I Diagnostic criteria for mild cognitive impairment

\begin{tabular}{|c|c|c|c|c|}
\hline Core diagnostic criteria & GDS $^{7,8}$ & Petersen et al $^{9}$ & Key Symposium" & NIA-AA $201 I^{21}$ \\
\hline Subjective cognitive complaint & + Memory & + Memory & + & + \\
\hline Objective cognitive impairment & $\begin{array}{l}\text { Memory; >I SD } \\
\text { below average }\end{array}$ & $\begin{array}{l}\text { Memory; > }>1.5 \text { SD } \\
\text { below average }\end{array}$ & $\begin{array}{l}\geq \text { I cognitive domain; no } \\
\text { recommended cut-off }\end{array}$ & $\begin{array}{l}\geq I \text { cognitive domain; } \\
\text { I-I.5 SD below average }\end{array}$ \\
\hline $\begin{array}{l}\text { Preserved general cognitive } \\
\text { performance }\end{array}$ & + & + & - & - \\
\hline Preserved functional independence & + & + & + & + \\
\hline Role of biomarkers & - & - & - & $\begin{array}{l}\text { Incorporated in } \\
\text { research criteria }\end{array}$ \\
\hline
\end{tabular}

Notes: -, criterion not required; +, required criterion.

Abbreviations: GDS, global deterioration scale; SD, standard deviation; NIA-AA, National Institute on Aging-Alzheimer's Association. 
of the apolipoprotein E (APOE) $\varepsilon 4$ allele, which is the most important genetic risk factor for $\mathrm{AD}$, has been associated with a more rapid conversion to $\mathrm{AD}$ in subjects with $\mathrm{MCI} .^{22,23}$ Abnormal CSF biomarkers, including lower $\beta$ amyloid 1-42 $\left(\mathrm{A} \beta_{42}\right)$, higher phosphorylated tau ${ }_{181}(\mathrm{P}$-tau $)$, and higher total tau ( $\mathrm{t}$-tau) were observed in MCI patients who later converted to $\mathrm{AD}^{24,25}$ or other dementia ${ }^{24}$ compared with non-convertors. Amyloid PET is another pathology-specific biomarker, and its positivity has been shown to predict later conversion to $\mathrm{AD}$ in subjects with MCI. ${ }^{26-29}$ Among biomarkers for neuronal injury, atrophy of medial temporal structures ${ }^{30-32}$ and hypometabolism in the temporo-parietal cortices ${ }^{33,34}$ were shown to predict a more rapid cognitive decline for subjects with MCI. Consistent with the risk stratification strategy proposed by the NIA-AA criteria, the combination of biomarkers for amyloid pathology and neuronal injury better predicted conversion to AD. ${ }^{35-38}$ In addition to biomarkers for Alzheimer's pathology and neurodegeneration, the association between modifiable vascular risk factors and cognitive deterioration in MCI has gained considerable interest in recent years. Epidemiological studies showed an inconsistent association between metabolic syndromes and the incidence of MCI. ${ }^{39}$ Meanwhile, several studies showed a higher conversion rate from MCI to AD or other types of dementia in subjects with diabetes $^{40-42}$ or other vascular risk factors. ${ }^{40,41}$ In addition, well-controlled diabetes, ${ }^{43}$ hypertension, ${ }^{41}$ and dyslipidemia ${ }^{41}$ were associated with a decreased risk of conversion to dementia. Whether vascular pathology is simply a comorbid condition with $\mathrm{AD}$ or is involved with the neurodegenerative process of $\mathrm{AD}$ is a burgeoning area of research.

\section{Subjective cognitive decline: moving toward a pre-MCl stage}

By defining MCI, recruited subjects could be objectively diagnosed at the earliest stage of cognitive impairment; however, randomized controlled trials for MCI patients have failed to find pharmacological treatments that are consistently effective at delaying cognitive decline. ${ }^{44-50}$ To stop the disease process, disease-modifying therapy may need to be initiated even before the onset of MCI. Prior to demonstrable cognitive impairment, many patients experience a subjective decline in memory or other cognitive domains. The subjective decline, even at the stage of normal cognitive performance, is associated with an increased risk of positive biomarkers for Alzheimer's pathology $y^{51-53}$ and later conversion to dementia. ${ }^{54-56}$ Subjects with subjective cognitive decline may be a reasonable target for therapeutic trials. Variable terminology has been used in previous studies to describe this pre-MCI stage, including subjective cognitive impairment, subjective memory decline, subjective memory impairment, and memory complaints. ${ }^{57}$ To generate comparability across studies, a consensus on the terminology and research criteria is crucial. In 2012, the Subjective Cognitive Decline Initiative (SCD-I) formed a working group to generate a common concept and terminology for SCD. ${ }^{58}$ The term "subjective cognitive decline" was suggested and was defined as a self-experienced persistent decline in cognitive capacity in comparison with the subject's previously normal status, during when the subject had normal age-, gender-, and education-adjusted performance on standardized cognitive tests. ${ }^{58}$ While preclinical AD can account for the subjective decline in cognition, many different physical and mental conditions can influence self-experienced cognitive fitness in the elderly. Several community and clinic-based epidemiology studies have demonstrated the association between cognitive complaint and depression, ${ }^{59-63}$ anxiety, ${ }^{59,61,63}$ and personality traits. ${ }^{59,62}$ Other comorbidities that may contribute to cognitive complaints include physical health, ${ }^{62,63}$ sleep problems, and concurrent medication use.

As an unspecific syndrome with multiple possible underlying etiologies, SCD cannot be considered equal to a prodromal phase of AD. Subjects with both cognitive complaints and concurrent $\mathrm{AD}$-associated pathological changes will be a better target for testing potential therapeutic agents, as they may be at a higher risk of further cognitive decline. The SCD-I working group used the term "SCD plus" to describe the following high-risk features: a subjective decline in memory, onset of SCD within the last 5 years, $>60$ years of age at SCD onset, concerns (worries) associated with SCD, feelings of worse performance than others in the same age group, confirmation of cognitive decline by an informant, presence of the APOE $\varepsilon 4$ genotype, and biomarker evidence for AD. ${ }^{58}$ These proposed high-risk features were selected based on our current knowledge of $\mathrm{AD}$, but they need further confirmation in longitudinal studies. A subjective complaint that is associated with concerns or supported by an informant may indicate a more significant decline from the baseline condition. In a community-based study that enrolled subjects aged $\geq 75$ years, Jessen et al reported a twofold increase in the risk of developing AD or any dementia for SCD subjects with worries, compared with those without worries. ${ }^{54}$ Confirmation of cognitive decline by an informant was not included as core criteria for SCD proposed by SCD-I. However, some studies showed that cognitive decline reported by an informant, ${ }^{64,65}$ or a mutual report from both the informant and the subject, ${ }^{66}$ 
may better predict conversion to $\mathrm{MCI}$ or $\mathrm{AD}$, compared with self-report. For subjects that later converted to MCI, Caselli et al observed that self-endorsed cognitive decline developed approximately 30 months earlier than that reported by the informants. ${ }^{65}$ The stronger predictive effect of an informant report may be partially explained by its association with a more advanced disease stage. Applying the SCD-plus criteria proposed by SCD-I, Fernandez-Blazquez et al showed a significantly higher risk of developing MCI in the following 13 months among subjects with SCD-plus (18.9\%; adjusted $\mathrm{HR}=4.2)$, compared with SCD alone $(5.6 \%){ }^{67}$

\section{Incorporating preclinical AD into subjective cognitive decline: strength and bias}

Biomarkers, including CSF profiles of $\mathrm{A} \beta_{42}$ and tau, amyloid PET positivity, atrophy of medial temporal structures, and hypometabolism in the temporo-parietal cortices, have been shown to predict a more rapid progression to dementia in subjects with MCI. However, the associations between these biomarkers and long-term cognitive outcomes in SCD subjects were not strong. Published longitudinal studies accessing the predictive value of AD biomarkers for cognitive outcome in SCD subjects are summarized in Table 2. As shown in subjects with MCI, APOE $\varepsilon 4$ allele carrier status is associated with an increased risk of conversion to MCI and $\mathrm{AD}$ in subjects with SCD. ${ }^{68-70} \mathrm{CSF}$ level of $\mathrm{A} \beta_{42}$ and tau protein were the most studied AD biomarkers. While van Harten et al reported that low $\mathrm{A} \beta_{42}$ was the strongest predictor of conversion to $\mathrm{MCI}$ or $\mathrm{AD},{ }^{71}$ Hessen et al and Rolstad et al found that high t-tau rather than $A \beta_{42}$ was correlated with future decline in memory and executive functions. ${ }^{72,73}$ Visser et al failed to find a significant association between abnormal $\mathrm{A} \beta_{42} /$ tau ratios and conversion to dementia, ${ }^{74}$ but only one SCD subject developed dementia during the 2.5-year follow-up period for that study. Neuroimaging biomarkers, including visual rating of hippocampal atrophy and white matter hyperintensities, ${ }^{70}$ gray matter atrophy pattern, ${ }^{75,76}$ diffusion tensor imaging, ${ }^{77}$ and hypometabolism on FDG PET, ${ }^{76}$ were evaluated as predictors of cognitive decline in a few studies. Scheef et al reported a significant association between hypometabolism in the right precuneus and verbal episodic memory decline 35 months later. ${ }^{76}$ The same study group later reported that a gray matter atrophy pattern

Table 2 Longitudinal studies for biomarkers and risk of cognitive decline in subjective cognitive decline subjects

\begin{tabular}{|c|c|c|c|c|c|}
\hline References & Profile & Definition & Duration & Endpoint & Results \\
\hline $\begin{array}{l}\text { van Harten et } a^{71} \\
(2013)\end{array}$ & $\begin{array}{l}n=127, \text { mean age } 60 \\
F 48 \% \text {, E4 33\% }\end{array}$ & $\mathrm{SC}$ and $\mathrm{I} .5 \mathrm{SD}$ & 4 years & $\mathrm{MCl}$ or $\mathrm{AD}$ & $\begin{array}{l}\text { CR I0\%; low } A \beta_{42}(H R=16) \text {, high t-tau } \\
(H R=2.8) \text {, high } p \text {-tau }(H R=2.6)\end{array}$ \\
\hline $\begin{array}{l}\text { Visser et } \mathrm{al}^{74} \\
(2009)\end{array}$ & $\begin{array}{l}n=60 \text {, mean age } 66 \\
F 48 \% \text {, E4 } 53 \%\end{array}$ & SC and I.5 SD & 2.5 years & $\begin{array}{l}\text { AD or non- } \\
\text { Alzheimer's } \\
\text { dementia }\end{array}$ & $\begin{array}{l}\text { CR } 0 \% \text { to } A D, 3 \% \text { to non-Alzheimer's } \\
\text { dementia; } A \beta_{42} / \text { t-tau (ns) }\end{array}$ \\
\hline $\begin{array}{l}\text { Sierra-Rio et } \mathrm{a}^{88} \\
(2016)\end{array}$ & $\begin{array}{l}n=55 \text {, mean age } 66 \\
F 73 \% \text {, E4 } 25 \%\end{array}$ & SC and I.5 SD & 42 vs 34 months & $\mathrm{MCl}$ or $\mathrm{AD}$ & $\begin{array}{l}\text { CR } 55 \% \text { vs } 18 \% \text { (abnormal } A \beta_{42} / \mathrm{P} \text {-tau ratio; } \\
\mathrm{OR}=27 . \mathrm{I} \text {; pooled data from } 55 \mathrm{SCD} \text { and } 94 \\
\mathrm{MCl} \text { subjects }\end{array}$ \\
\hline $\begin{array}{l}\text { Hessen et } \mathrm{al}^{72} \\
(2015)\end{array}$ & $\begin{array}{l}n=122 \text {, mean age } 62.5, \\
F 55 \%\end{array}$ & SC and I.3 SD & 2 years & $\begin{array}{l}\text { Decline of } M \text { or } E \\
\text { for } 0.5 \mathrm{SD}\end{array}$ & Tau predicts $M$ decline $(P=0.046) ; A \beta_{42}(n s)$ \\
\hline $\begin{array}{l}\text { Rolstad et } \mathrm{al}^{73} \\
(2013)\end{array}$ & $\begin{array}{l}n=82 \text {, mean age } 66, \\
F 54 \%\end{array}$ & $\begin{array}{l}\text { SC and GDS } \\
\text { stage } 2\end{array}$ & 2 years & $\begin{array}{l}\text { Decline of } M, E \text {, } \\
\text { VS, V, or WM }\end{array}$ & $\begin{array}{l}\text { Tau predicts } E \text { decline }\left(r^{2}=0.07, P=0.03\right) \\
\mathrm{A} \beta_{42} \text { (ns) }\end{array}$ \\
\hline $\begin{array}{l}\text { Scheef et } \mathrm{al}^{76} \\
(2012)\end{array}$ & $\begin{array}{l}n=27 \text {, mean age } 67, \\
F 42 \% \text {, E4 33\% }\end{array}$ & $\begin{array}{l}\text { Worries }(+) \text {, } \\
\text { informant }(+) \text {, } \\
\text { and I.5 SD }\end{array}$ & 36 months & Decline of $M$ or $E$ & $\begin{array}{l}\text { PET hypometabolism at right precuneus } \\
\text { predicts } M \text { decline }(P=0.029), M R I \\
\text { hippocampal gray matter (ns) }\end{array}$ \\
\hline $\begin{array}{l}\text { Peter et al }{ }^{75} \\
(2014)\end{array}$ & $\begin{array}{l}n=24 \text {, mean age } 60 \text {, } \\
F 75 \% \text {, E4 } 29 \%\end{array}$ & $\begin{array}{l}\text { Worries }(+) \text {, } \\
\text { informant }(+) \text {, } \\
\text { and I.5 SD }\end{array}$ & 34 months & Decline of $M$ or $E$ & $\begin{array}{l}\text { MRI AD gray matter pattern predicts } \\
\text { M decline }(P=0.12)\end{array}$ \\
\hline $\begin{array}{l}\text { Selnes et } \mathrm{al}^{77} \\
(2013)\end{array}$ & $\begin{array}{l}\mathrm{n}=\mathrm{II} \text {, mean age } 6 \mathrm{I}, \\
\mathrm{F} 73 \% \text {, E4 55\% }\end{array}$ & $\begin{array}{l}\text { SC and GDS } \\
\text { stage } 2\end{array}$ & $2-3$ years & $\begin{array}{l}\mathrm{MCl} \text { or } \mathrm{AD} \\
\text { decline of } \mathrm{MMSE}\end{array}$ & $\begin{array}{l}\text { CR } 27 \% \text { to } \mathrm{MCl}, 45 \% \text { to } \mathrm{AD} \text {; DTI and } \\
\text { t-tau predict cognitive decline and medial } \\
\text { temporal lobe atrophy (I I SCD and } 43 \mathrm{MCl} \text { ) }\end{array}$ \\
\hline $\begin{array}{l}\text { Hong et } \mathrm{al}^{70} \\
(2015)\end{array}$ & $\begin{array}{l}n=129, \text { mean age } 66 \\
F \text { 65\%, E4 } 29 \%\end{array}$ & SC and I.0 SD & 3.6 years & $\mathrm{MCl}$ or $\mathrm{AD}$ & $\begin{array}{l}\text { CR } 22 \% \text {; MRI visual rating of hippocampal } \\
\text { atrophy and } \mathrm{WMH} \text { (ns) }\end{array}$ \\
\hline
\end{tabular}

Notes: SD is used to define normal cognitive performance. + , criterion required to define study population.

Abbreviations: $A \beta_{42}, \beta$ amyloid I-42; AD, Alzheimer's disease; CR, conversion rate; DTI, diffusion tensor imaging; E, executive function; E4, apolipoprotein E ع4 allele carrier; F, female; GDS, Global Deterioration Scale; HR, hazard ratio associated with biomarkers; M, memory; MCl, mild cognitive impairment; MMSE, Mini-Mental State Examination; ns, nonsignificant; MRI, magnetic resonance imaging; OR, odds ratio asssociated with biomarkers; PET, positron emission tomography; p-tau, phosphorylated tau I8I; SC, subjective complaint; SCD, subjective cognitive decline; SD, standard deviation; t-tau, total tau; $\mathrm{V}$, verbal function; VS, visuospatial function; WM, working memory; WMH, white matter hyperintensity. 
similar to that observed in $\mathrm{AD}$ was associated with episodic memory decline. ${ }^{75}$ Hong et al tested visual rating scores for hippocampal atrophy and white matter hyperintensities to predict conversion to $\mathrm{MCI}$ and $\mathrm{AD}$, but failed to show a significant association. ${ }^{70}$ In summary, current evidence suggests that low CSF $\mathrm{A} \beta_{42}$ and high t-tau or p-tau may help predict cognitive decline in SCD subjects, while the evidence for neuroimaging biomarkers is limited. The low conversion rate to dementia reported by previous studies reflects the early preclinical nature of SCD. Future studies should use longer follow-up periods or apply more sensitive measures for cognitive decline to establish the validity of biomarkers for cognitive prediction in SCD.

While incorporation of biomarkers for preclinical AD may help specify SCD subjects carrying an increased risk of progression to dementia, this approach is based on the hypothetical model of neurodegeneration following the amyloid cascade. ${ }^{4,6}$ In recent years, emerging evidence suggests that some subjects with subtle cognitive decline or MCI have biomarker profiles inconsistent with the hypothetical model for preclinical AD. These subjects, referred to as "suspected non-AD pathophysiology (SNAP)," present with neurodegeneration but are negative for biomarkers of amyloid pathology. ${ }^{78}$ Petersen et al analyzed MCI subjects from The Mayo Clinic Study of Aging cohort and found that 29\% of MCI subjects exhibited neurodegeneration without amyloid deposition. ${ }^{79}$ In addition, these MCI subjects with neurodegeneration-only biomarker profiles had an increased risk of progression to $\mathrm{AD}$, similar to subjects with both amyloid and neurodegeneration biomarkers. Alternatively, Landau et al extracted data from MCI and AD patients with negative florbetapir-PET from the Alzheimer's Disease Neuroimaging Initiative cohort and found that these patients were less likely to be APOE \&4-positive, had less AD-specific hypometabolism, and had better longitudinal cognitive performance. ${ }^{80}$ These reports of conflicting biomarker profiles suggest a neurodegeneration pathway independent of amyloid pathology, or underlying non-AD pathology. More longitudinal studies will be needed to determine the long-term cognitive outcomes in amyloid-negative subjects. Studies using biomarkers as inclusion criteria may embed a selection bias that excludes SCD subjects with conflicting biomarker profiles.

\section{Measurement of subjective changes}

Various questionnaires have been used in previous studies to measure subjective changes in cognitive capacity. The SCD-I working group reviewed cognitive self-report measurements used in previous studies and found significant heterogeneity among studies ${ }^{81}$ Measurements differ in response options, duration of reference timeframe, cognitive items assessed, and item specificity. Many measures were used only in a single study, ${ }^{82-84}$ while the Memory Complaint Questionnaire (MAC-Q) $)^{85}$ and the Everyday Cognition Scale (ECog) ${ }^{86}$ were the most commonly used assessments across different studies. Most of these questionnaires were developed recently and lack validation between different populations and cultures. In addition, very few studies have addressed the consistency and compatibility of different questionnaires. ${ }^{87}$ The SCD-I working group offered several recommendations for measurement selection. ${ }^{81}$ Measures should be validated for the target population, simple and easy to understand, inquire more about the cognitive issues that older adults encounter in their daily lives, sample cognitive domains beyond episodic memory, and have a specific and narrow reference period. Researchers should also use caution when comparing outcomes between studies using different measurements.

\section{Conclusion and prospective}

During the past two decades, the clinical spectrum of AD has been extended to include MCI and even further extended to include SCD. Extending the disease spectrum to the early stages reflects the need to identify and introduce diseasemodifying therapy before an irreversible degenerative process occurs. While the concept of SCD was developed to broaden the AD spectrum, it also includes a broad range of underlying etiologies, including non-AD dementia, mood problems, and physical health conditions. The application of biomarkers to patients with SCD may help specify individuals with underlying Alzheimer's pathology. Meanwhile, SCD can be applied to non-AD dementia and may provide an opportunity to study how different pathological processes interact to influence cognitive outcomes.

\section{Disclosure}

The authors report no conflicts of interest in this work.

\section{References}

1. Mangialasche F, Solomon A, Winblad B, Mecocci P, Kivipelto M Alzheimer's disease: clinical trials and drug development. Lancet Neurol. 2010;9(7):702-716.

2. Schneider LS, Mangialasche F, Andreasen N, et al. Clinical trials and late-stage drug development for Alzheimer's disease: an appraisal from 1984 to 2014. J Intern Med. 2014;275(3):251-283.

3. Price JL, Morris JC. Tangles and plaques in nondemented aging and "preclinical" Alzheimer's disease. Ann Neurol. 1999;45(3):358-368.

4. Jack CR Jr, Knopman DS, Jagust WJ, et al. Hypothetical model of dynamic biomarkers of the Alzheimer's pathological cascade. Lancet Neurol. 2010;9(1):119-128. 
5. Bateman RJ, Xiong C, Benzinger TL, et al. Clinical and biomarker changes in dominantly inherited Alzheimer's disease. NEngl JMed.2012; 367(9):795-804.

6. Sperling RA, Aisen PS, Beckett LA, et al. Toward defining the preclinical stages of Alzheimer's disease: recommendations from the National Institute on Aging-Alzheimer's Association workgroups on diagnostic guidelines for Alzheimer's disease. Alzheimer's Dement. 2011; 7(3):280-292.

7. Reisberg B, Ferris SH, de Leon MJ, Crook T. The global deterioration scale for assessment of primary degenerative dementia. Am JPsychiatry. 1982;139(9):1136-1139.

8. Flicker C, Ferris SH, Reisberg B. Mild cognitive impairment in the elderly: predictors of dementia. Neurology. 1991;41(7):1006-1009.

9. Petersen RC, Smith GE, Waring SC, Ivnik RJ, Tangalos EG, Kokmen E. Mild cognitive impairment: clinical characterization and outcome. Arch Neurol. 1999;56(3):303-308.

10. Petersen RC. Mild cognitive impairment as a diagnostic entity. J Intern Med. 2004;256(3):183-194.

11. Winblad B, Palmer K, Kivipelto M, et al. Mild cognitive impairmentbeyond controversies, towards a consensus: report of the International Working Group on Mild Cognitive Impairment. J Intern Med. 2004; 256(3):240-246.

12. Ward A, Arrighi HM, Michels S, Cedarbaum JM. Mild cognitive impairment: disparity of incidence and prevalence estimates. Alzheimer's Dement. 2012;8(1):14-21.

13. Petersen RC, Caracciolo B, Brayne C, Gauthier S, Jelic V, Fratiglioni L. Mild cognitive impairment: a concept in evolution. J Intern Med. 2014; 275(3):214-228

14. Sun Y, Lee HJ, Yang SC, et al. A nationwide survey of mild cognitive impairment and dementia, including very mild dementia, in Taiwan. PLoS one. 2014;9(6):e100303.

15. Ward A, Tardiff S, Dye C, Arrighi HM. Rate of conversion from prodromal Alzheimer's disease to Alzheimer's dementia: a systematic review of the literature. Dement Geriatr Cogn Dis Extra. 2013;3(1):320-332.

16. Tifratene K, Robert P, Metelkina A, Pradier C, Dartigues JF. Progression of mild cognitive impairment to dementia due to $\mathrm{AD}$ in clinical settings. Neurology. 2015;85(4):331-338.

17. Vos SJ, van Rossum IA, Verhey F, et al. Prediction of Alzheimer disease in subjects with amnestic and nonamnestic MCI. Neurology. 2013;80(12): 1124-1132.

18. Ravaglia G, Forti P, Maioli F, et al. Conversion of mild cognitive impairment to dementia: predictive role of mild cognitive impairment subtypes and vascular risk factors. Dement Geriatr Cogn Disord. 2006;21(1):51-58.

19. Busse A, Hensel A, Guhne U, Angermeyer MC, Riedel-Heller SG. Mild cognitive impairment: long-term course of four clinical subtypes. Neurology. 2006;67(12):2176-2185.

20. McKhann GM, Knopman DS, Chertkow H, et al. The diagnosis of dementia due to Alzheimer's disease: recommendations from the National Institute on Aging-Alzheimer's Association workgroups on diagnostic guidelines for Alzheimer's disease. Alzheimer's Dement. 2011;7(3):263-269.

21. Albert MS, DeKosky ST, Dickson D, et al. The diagnosis of mild cognitive impairment due to Alzheimer's disease: recommendations from the National Institute on Aging-Alzheimer's Association workgroups on diagnostic guidelines for Alzheimer's disease. Alzheimer's Dement. 2011;7(3):270-279.

22. Petersen RC, Smith GE, Ivnik RJ, et al. Apolipoprotein E status as a predictor of the development of Alzheimer's disease in memoryimpaired individuals. JAMA. 1995;273(16):1274-1278.

23. Da X, Toledo JB, Zee J, et al. Integration and relative value of biomarkers for prediction of MCI to AD progression: spatial patterns of brain atrophy, cognitive scores, APOE genotype and CSF biomarkers. Neuroimage Clin. 2014;4:164-173.

24. Hansson O, Zetterberg H, Buchhave P, Londos E, Blennow K, Minthon L. Association between CSF biomarkers and incipient Alzheimer's disease in patients with mild cognitive impairment: a follow-up study. Lancet Neurol. 2006;5(3):228-234.
25. Mattsson N, Zetterberg H, Hansson O, et al. CSF biomarkers and incipient Alzheimer disease in patients with mild cognitive impairment. JAMA. 2009;302(4):385-393.

26. Forsberg A, Engler H, Almkvist O, et al. PET imaging of amyloid deposition in patients with mild cognitive impairment. Neurobiol Aging. 2008;29(10):1456-1465.

27. Grimmer T, Wutz C, Drzezga A, et al. The usefulness of amyloid imaging in predicting the clinical outcome after two years in subjects with mild cognitive impairment. Curr Alzheimer Res. 2013;10(1):82-85.

28. Nordberg A, Carter SF, Rinne J, et al. A European multicentre PET study of fibrillar amyloid in Alzheimer's disease. Eur J Nucl Med Mol Imaging. 2013;40(1):104-114.

29. Landau SM, Mintun MA, Joshi AD, et al. Amyloid deposition, hypometabolism, and longitudinal cognitive decline. Ann Neurol. 2012;72(4): $578-586$.

30. Frisoni GB, Fox NC, Jack CR Jr, Scheltens P, Thompson PM. The clinical use of structural MRI in Alzheimer disease. Nat Rev Neurol. 2010;6(2):67-77.

31. Leung KK, Bartlett JW, Barnes J, Manning EN, Ourselin S, Fox NC. Cerebral atrophy in mild cognitive impairment and Alzheimer disease: rates and acceleration. Neurology. 2013;80(7):648-654.

32. Eskildsen SF, Coupe P, Garcia-Lorenzo D, Fonov V, Pruessner JC, Collins DL. Prediction of Alzheimer's disease in subjects with mild cognitive impairment from the ADNI cohort using patterns of cortical thinning. NeuroImage. 2013;65:511-521.

33. Landau SM, Harvey D, Madison CM, et al. Comparing predictors of conversion and decline in mild cognitive impairment. Neurology. 2010; 75(3):230-238

34. Herholz K. Cerebral glucose metabolism in preclinical and prodromal Alzheimer's disease. Expert Rev Neurother. 2010;10(11):1667-1673.

35. Prestia A, Caroli A, van der Flier WM, et al. Prediction of dementia in MCI patients based on core diagnostic markers for Alzheimer disease. Neurology. 2013;80(11):1048-1056.

36. Shaffer JL, Petrella JR, Sheldon FC, et al. Predicting cognitive decline in subjects at risk for Alzheimer disease by using combined cerebrospinal fluid, MR imaging, and PET biomarkers. Radiology. 2013; 266(2):583-591.

37. Choo IH, Ni R, Scholl M, Wall A, Almkvist O, Nordberg A. Combination of 18F-FDG PET and cerebrospinal fluid biomarkers as a better predictor of the progression to Alzheimer's disease in mild cognitive impairment patients. J Alzheimer's Dis. 2013;33(4):929-939.

38. Vos SJ, Verhey F, Frolich L, et al. Prevalence and prognosis of Alzheimer's disease at the mild cognitive impairment stage. Brain. 2015; 138(Pt 5):1327-1338

39. Misiak B, Leszek J, Kiejna A. Metabolic syndrome, mild cognitive impairment and Alzheimer's disease - the emerging role of systemic low-grade inflammation and adiposity. Brain Res Bull. 2012;89(3-4):144-149.

40. Ng TP, Feng L, Nyunt MS, et al. Metabolic syndrome and the risk of mild cognitive impairment and progression to dementia: follow-up of the Singapore longitudinal ageing study cohort. JAMA Neurol. 2016; 73(4):456-463.

41. Li J, Wang YJ, Zhang M, et al. Vascular risk factors promote conversion from mild cognitive impairment to Alzheimer disease. Neurology. 2011; 76(17):1485-1491.

42. Cooper C, Sommerlad A, Lyketsos CG, Livingston G. Modifiable predictors of dementia in mild cognitive impairment: a systematic review and meta-analysis. Am J Psychiatry. 2015;172(4):323-334.

43. Ma F, Wu T, Miao R, Xiao YY, Zhang W, Huang G. Conversion of mild cognitive impairment to dementia among subjects with diabetes: a population-based study of incidence and risk factors with five years of follow-up. J Alzheimer's Dis. 2015;43(4):1441-1449.

44. Doody RS, Ferris SH, Salloway S, et al. Donepezil treatment of patients with MCI: a 48-week randomized, placebo-controlled trial. Neurology. 2009;72(18):1555-1561.

45. Feldman HH, Ferris S, Winblad B, et al. Effect of rivastigmine on delay to diagnosis of Alzheimer's disease from mild cognitive impairment: the InDDEx study. Lancet Neurol. 2007;6(6):501-512. 
46. Petersen RC, Thomas RG, Grundman M, et al. Vitamin E and donepezil for the treatment of mild cognitive impairment. $N$ Engl J Med. 2005; 352(23):2379-2388.

47. Thal LJ, Ferris SH, Kirby L, et al. A randomized, double-blind, study of rofecoxib in patients with mild cognitive impairment. Neuropsychopharmacology. 2005;30(6):1204-1215.

48. Winblad B, Gauthier S, Scinto L, et al. Safety and efficacy of galantamine in subjects with mild cognitive impairment. Neurology. 2008;70(22): 2024-2035.

49. Farina N, Isaac MG, Clark AR, Rusted J, Tabet N. Vitamin E for Alzheimer's dementia and mild cognitive impairment. Cochrane Database Syst Rev. 2012;11:Cd002854.

50. Eshkoor SA, Hamid TA, Mun CY, Ng CK. Mild cognitive impairment and its management in older people. Clin Interv Aging. 2015;10 687-693.

51. Mielke MM, Wiste HJ, Weigand SD, et al. Indicators of amyloid burden in a population-based study of cognitively normal elderly. Neurology. 2012;79(15):1570-1577.

52. Stewart R, Godin O, Crivello F, et al. Longitudinal neuroimaging correlates of subjective memory impairment: 4-year prospective community study. Br J Psychiatry. 2011;198(3):199-205.

53. Sun Y, Yang FC, Lin CP, Han Y. Biochemical and neuroimaging studies in subjective cognitive decline: progress and perspectives. CNS Neurosci Ther. 2015;21(10):768-775.

54. Jessen F, Wiese B, Bachmann C, et al. Prediction of dementia by subjective memory impairment: effects of severity and temporal association with cognitive impairment. Arch Gen Psychiatry. 2010; 67(4):414-422.

55. Reisberg B, Shulman MB, Torossian C, Leng L, Zhu W. Outcome over seven years of healthy adults with and without subjective cognitive impairment. Alzheimer's Dement. 2010;6(1):11-24.

56. Mitchell AJ, Beaumont H, Ferguson D, Yadegarfar M, Stubbs B. Risk of dementia and mild cognitive impairment in older people with subjective memory complaints: meta-analysis. Acta Psychiatr Scand. 2014;130(6):439-451.

57. Abdulrab K, Heun R. Subjective Memory Impairment. A review of its definitions indicates the need for a comprehensive set of standardised and validated criteria. Eur Psychiatry. 2008;23(5):321-330.

58. Jessen F, Amariglio RE, van Boxtel M, et al. A conceptual framework for research on subjective cognitive decline in preclinical Alzheimer's disease. Alzheimer's Dement. 2014;10(6):844-852.

59. Slavin MJ, Brodaty H, Kochan NA, et al. Prevalence and predictors of "subjective cognitive complaints" in the Sydney memory and ageing study. Am J Geriatr Psychiatry. 2010;18(8):701-710.

60. Hohman TJ, Beason-Held LL, Resnick SM. Cognitive complaints, depressive symptoms, and cognitive impairment: are they related? J Am Geriatr Soc. 2011;59(10):1908-1912.

61. Buckley R, Saling MM, Ames D, et al. Factors affecting subjective memory complaints in the AIBL aging study: biomarkers, memory, affect, and age. Int Psychogeriatr. 2013;25(8):1307-1315.

62. Stogmann E, Moser D, Klug S, et al. Activities of daily living and depressive symptoms in patients with subjective cognitive decline, mild cognitive impairment, and Alzheimer's disease. J Alzheimer's Dis 2015;49(4):1043-1050.

63. Comijs HC, Deeg DJ, Dik MG, Twisk JW, Jonker C. Memory complaints; the association with psycho-affective and health problems and the role of personality characteristics: a 6-year follow-up study. J Affect Disord. 2002;72(2):157-165.

64. Slavin MJ, Sachdev PS, Kochan NA, et al. Predicting cognitive, functional, and diagnostic change over 4 Years using baseline subjective cognitive complaints in the Sydney memory and ageing study. Am J Geriatr Psychiatry. 2015;23(9):906-914.

65. Caselli RJ, Chen K, Locke DE, et al. Subjective cognitive decline: self and informant comparisons. Alzheimer's Dement 2014;10(1):93-98.

66. Gifford KA, Liu D, Hohman TJ, et al. A mutual self- and informantreport of cognitive complaint correlates with neuropathological outcomes in mild cognitive impairment. PLoS One. 2015;10(11):e0141831.
67. Fernandez-Blazquez MA, Avila-Villanueva M, Maestu F, Medina M. Specific features of subjective cognitive decline predict faster conversion to mild cognitive impairment. J Alzheimer's Dis. 2016;52(1):271-281.

68. Kryscio RJ, Abner EL, Cooper GE, et al. Self-reported memory complaints: implications from a longitudinal cohort with autopsies. Neurology. 2014;83(15):1359-1365.

69. Dik MG, Jonker C, Comijs HC, et al. Memory complaints and APOEepsilon4 accelerate cognitive decline in cognitively normal elderly. Neurology. 2001;57(12):2217-2222.

70. Hong YJ, Yoon B, Shim YS, et al. Predictors of clinical progression of subjective memory impairment in elderly subjects: data from the clinical research centers for dementia of South Korea (CREDOS). Dement Geriatr Cogn Disord. 2015;40(3-4):158-165.

71. van Harten AC, Visser PJ, Pijnenburg YA, et al. Cerebrospinal fluid Abeta42 is the best predictor of clinical progression in patients with subjective complaints. Alzheimer's Dement. 2013;9(5):481-487.

72. Hessen E, Nordlund A, Stalhammar J, et al. T-Tau is associated with objective memory decline over two years in persons seeking help for subjective cognitive decline: a report from the Gothenburg-Oslo MCI study. J Alzheimer's Dis. 2015;47(3):619-628.

73. Rolstad S, Berg AI, Bjerke M, Johansson B, Zetterberg H, Wallin A. Cerebrospinal fluid biomarkers mirror rate of cognitive decline. J Alzheimer's Dis. 2013;34(4):949-956.

74. Visser PJ, Verhey F, Knol DL, et al. Prevalence and prognostic value of CSF markers of Alzheimer's disease pathology in patients with subjective cognitive impairment or mild cognitive impairment in the DESCRIPA study: a prospective cohort study. Lancet Neurol. 2009;8(7): 619-627.

75. Peter J, Scheef L, Abdulkadir A, et al; Alzheimer's Disease Neuroimaging Initiative. Gray matter atrophy pattern in elderly with subjective memory impairment. Alzheimer's Dement. 2014;10(1):99-108.

76. Scheef L, Spottke A, Daerr M, et al. Glucose metabolism, gray matter structure, and memory decline in subjective memory impairment. Neurology. 2012;79(13):1332-1339.

77. Selnes P, Aarsland D, Bjornerud A, et al. Diffusion tensor imaging surpasses cerebrospinal fluid as predictor of cognitive decline and medial temporal lobe atrophy in subjective cognitive impairment and mild cognitive impairment. J Alzheimer's Dis. 2013;33(3):723-736.

78. Jack CR Jr, Knopman DS, Weigand SD, et al. An operational approach to National Institute on Aging-Alzheimer's Association criteria for preclinical Alzheimer disease. Ann Neurol. 2012;71(6):765-775.

79. Petersen RC, Aisen P, Boeve BF, et al. Mild cognitive impairment due to Alzheimer disease in the community. Ann Neurol. 2013;74(2): 199-208.

80. Landau SM, Horng A, Fero A, Jagust WJ; Alzheimer's Disease Neuroimaging Initiative. Amyloid negativity in patients with clinically diagnosed Alzheimer disease and MCI. Neurology. 2016;86(15): 1377-1385.

81. Rabin LA, Smart CM, Crane PK, et al. Subjective cognitive decline in older adults: an overview of self-report measures used across 19 international research studies. J Alzheimer's Dis. 2015;48(Suppl 1):S63-S86.

82. Rami L, Mollica MA, Garcia-Sanchez C, et al. The Subjective Cognitive Decline Questionnaire (SCD-Q): a validation study. J Alzheimer's Dis. 2014;41(2):453-466.

83. Morris JC, Heyman A, Mohs RC, et al. The consortium to establish a registry for Alzheimer's disease (CERAD). Part I. Clinical and neuropsychological assessment of Alzheimer's disease. Neurology. 1989;39(9): 1159-1165.

84. Jessen F, Wiese B, Cvetanovska G, et al. Patterns of subjective memory impairment in the elderly: association with memory performance. Psychol Med. 2007;37(12):1753-1762.

85. Crook TH, Feher EP, Larrabee GJ. Assessment of memory complaint in age-associated memory impairment: the MAC-Q. Int Psychogeriatr. 1992;4(2):165-176.

86. Farias ST, Mungas D, Reed BR, et al. The measurement of everyday cognition (ECog): scale development and psychometric properties. Neuropsychology. 2008;22(4):531-544. 
87. Vogel A, Salem LC, Andersen BB, Waldemar G. Differences in quantitative methods for measuring subjective cognitive decline - results from a prospective memory clinic study. Int Psychogeriatr. 2016;28(9): 1513-1520.
88. Sierra-Rio A, Balasa M, Olives J, et al. Cerebrospinal fluid biomarkers predict clinical evolution in patients with subjective cognitive decline and mild cognitive impairment. Neurodegener Dis. 2016;16(1-2):69-76.

\section{Publish your work in this journal}

Neuropsychiatric Disease and Treatment is an international, peerreviewed journal of clinical therapeutics and pharmacology focusing on concise rapid reporting of clinical or pre-clinical studies on a range of neuropsychiatric and neurological disorders. This journal is indexed on PubMed Central, the 'PsycINFO' database and CAS, and is the official journal of The International Neuropsychiatric Association (INA). The manuscript management system is completely online and includes a very quick and fair peer-review system, which is all easy to use. Visit http://www.dovepress.com/testimonials.php to read real quotes from published authors.

Submit your manuscript here: http://www.dovepress.com/neuropsychiatric-disease-and-treatment-journal 